$09 ; 14$

\title{
Исследование показателя преломления обезвоженных клеток с помощью цифровой голографической микроскопии
}

\author{
(C) А.В. Белашов ${ }^{1,2}$, А.А. Жихорева ${ }^{1,2}$, В.Г. Беспалов ${ }^{4}$, \\ О.С. Васютинский ${ }^{1}$, Н.Т. Жилинская ${ }^{3,4}$, \\ В.И. Новик ${ }^{4}$, И.В. Семенова ${ }^{1, \uparrow}$ \\ ${ }^{1}$ Физико-технический институт им. А.Ф. Иоффе РАН, Санкт-Петербург \\ ${ }^{2}$ Университет ИТМО, \\ Санкт-Петербург \\ ${ }^{3}$ Санкт-Петербургский политехнический университет Петра Великого \\ ${ }^{4}$ НИИ онкологии им. Н.Н. Петрова, Санкт-Петербург \\ ฯ E-mail: irina.semenova@mail.ioffe.ru
}

Поступило в Редакцию 24 мая 2017 г.

$\mathrm{C}$ помощью метода цифровой голографической микроскопии получены пространственные распределения интегрального показателя преломления обезвоженных клеток эпителия ротовой полости человека и определен их средний показатель преломления. Проведен статистический анализ полученных данных и оценена абсолютная погрешность метода для различных условий эксперимента.

DOI: 10.21883/PJTF.2017.20.45149.16886

В последние годы цифровая голографическая микроскопия находит широкое применение в биологических исследованиях [1,2], а также в работах, связанных с медицинскими приложениями, в частности при диагностике целого ряда заболеваний $[3,4]$. В отличие от оптической микроскопии голографическая микроскопия позволяет получать количественные данные о фазовом запаздывании волнового фронта, прошедшего через клеточные структуры, что широко используется при наблюдении различных биологических процессов $[5,6]$. Измеряемой физической величиной в голографических методах является показатель преломления, определение пространственных распределений которого дает возможность получить важную дополнительную информацию по сравнению с другими оптическими методами. Таким образом, показатель преломления является важным параметром, характеризующим 
биологические объекты, и, как было показано в ряде работ, его отклонение от типичных для данного типа клеток значений может служить признаком различного рода патологий $[1,7]$.

Для измерения показателя преломления однородных сред обычно используются рефрактометры, однако их применение при исследовании внутриклеточных структур затруднительно. Значительно более перспективным для этой цели является использование методов цифровой голографической микроскопии. Вместе с тем, однозначное определение показателя преломления возможно лишь при наличии дополнительной информации о толщине объекта, которая может быть получена, например, с помощью конфокальной флуоресцентной микроскопии [8]. Определение показателя преломления также возможно при использовании нескольких оптических сред с различными показателями преломления [9]. При этом производится регистрация и восстановление цифровых голограмм исследуемого объекта, помещенного в различные среды, с последующим получением данных о толщине и интегральном показателе преломления в каждой точке посредством решения системы уравнений. Использование этих подходов позволило установить, что средний показатель преломления большинства живых клеток лежит в диапазоне 1.36-1.38 [8,10-12]. До сих пор подобные исследования проводились лишь на живых клетках, содержащих значительное количество воды.

В настоящей работе представлены результаты определения интегрального показателя преломления обезвоженных клеток эпителия ротовой полости человека методом цифровой голографической микроскопии. Полученные результаты представляют интерес как для разработки новых методов диагностики патологических изменений клеток, так и для идентификации живых и мертвых клеток, а также определения процентного содержания в них воды. Исследование обезвоженных образцов может повысить точность диагностики, поскольку патологические процессы, очевидно, не приводят к изменению показателя преломления воды, но могут сказываться на показателе преломления сухих составляющих клетки. Таким образом, решение задачи измерения распределений показателя преломления в обезвоженных клетках позволит расширить спектр приложений и точность данного метода при изучении биологических объектов.

Материалом для цитологического исследования служили соскобы с интактной слизистой оболочки полости рта щеки мужчины 45

Письма в ЖТФ, 2017, том 43, вып. 20 


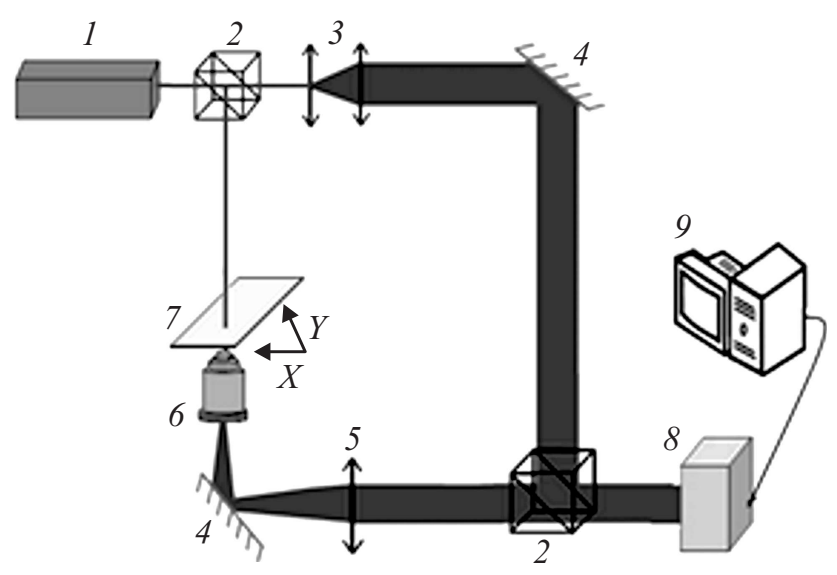

Рис. 1. Оптическая установка. 1 - лазер, 2 - делители пучка, 3 - расширитель пучка, 4 - зеркала, 5 - коллимирующая линза, 6 - микрообъектив, 7 - образец, $8-\mathrm{CCD}$-камера, 9 - компьютер.

лет без признаков воспаления и других патологических изменений полости рта. Соскобы производили стерильным ватным тампоном, наносили на предметное обезжиренное стекло, высушивали в течение $10 \min$ и фиксировали в смеси $96 \%$ этилового спирта и медицинского эфира в соотношении $1: 1$ в течение $10 \mathrm{~min}$ [13]. Фиксированные неокрашенные препараты использовались для исследования с помощью цифрового голографического микроскопа, представляющего собой комбинацию инвертированного оптического микроскопа и интерферометра Маха-Цандера, блок-схема которого представлена на рис. 1. Сканирование образцов осуществлялось с помощью двухкоординатной моторизированной подвижки. Для повышения качества получаемых данных и уменьшения влияния когерентного шума при восстановлении голограмм использовался метод фильтрации с обратным сдвигом [14]. После регистрации и обработки серии цифровых голограмм методами, описанными нами в работе [15], проводилось усреднение полученных данных по 49 фазовым распределениям.

Измерения показателя преломления клеток выполнялись в два этапа. Сначала проводилась регистрация распределений фазового сдвига,

Письма в ЖТФ, 2017, том 43, вып. 20 
вносимого в волновой фронт клетками, находящимися в воздушной среде. Затем к предметному стеклу с образцом прикладывалось покровное стекло с каплей физиологического раствора (0.9\% раствор хлорида натрия в воде). В результате действия сил поверхностного натяжения происходило равномерное распределение жидкости по всей площади покровного стекла. Горизонтальное положение предметного стекла с образцами позволило предотвратить сползание клеток и вытекание физиологического раствора. Проводилась регистрация распределений фазового сдвига в тех же клетках, но находящихся в среде физиологического раствора. Затем по двум полученным распределениям фазовых набегов определялись значения интегрального показателя преломления и толщины клетки в каждой точке с помощью выражений:

$$
\left\{\begin{array}{l}
l=\frac{\lambda}{2 \pi} \frac{\Delta \varphi_{1}-\Delta \varphi_{2}}{n_{m 1}-n_{m 2}} \\
n_{c}=\frac{\Delta \varphi_{1} n_{m 2}-\Delta \varphi_{2} n_{m 1}}{\Delta \varphi_{1}-\Delta \varphi_{2}} .
\end{array}\right.
$$

Здесь $\lambda$ - длина волны регистрирующего излучения, $\Delta \varphi_{1}$ и $\Delta \varphi_{2}-$ измеренные значения фазового запаздывания волнового фронта в средах с показателями преломления $n_{m 1}$ и $n_{m 2}$ соответственно. Искомые параметры клетки - интегральный показатель преломления и толщина обозначены соответственно как $n_{c}$ и $l$.

Примеры полученных распределений интегрального показателя преломления и толщины клетки представлены на рис. 2. В работе было исследовано семь клеток образца, после усреднения по полученным данным было построено статистическое распределение интегрального показателя преломления в клетках данного вида, приведенное на рис. 3 .

Средний показатель преломления сухих клеток эпителия ротовой полости был оценен как $n_{c}=1.478$ с вариацией этой величины по отдельным клеткам из данной выборки $\Delta n=0.025$. Принимая во внимание используемые в работе методы усреднения по нескольким фазовым распределениям, мы установили, что погрешность измерения фазового сдвига, внесенного клетками в волновой фронт, составляет порядка $0.05 \mathrm{rad}$.

Необходимо отметить, что обезвоженные клетки, исследуемые в настоящей работе, обладают бо́льшим средним интегральным показателем преломления, чем живые клетки, где концентрация воды

4 Письма в ЖТФ, 2017, том 43, вып. 20 

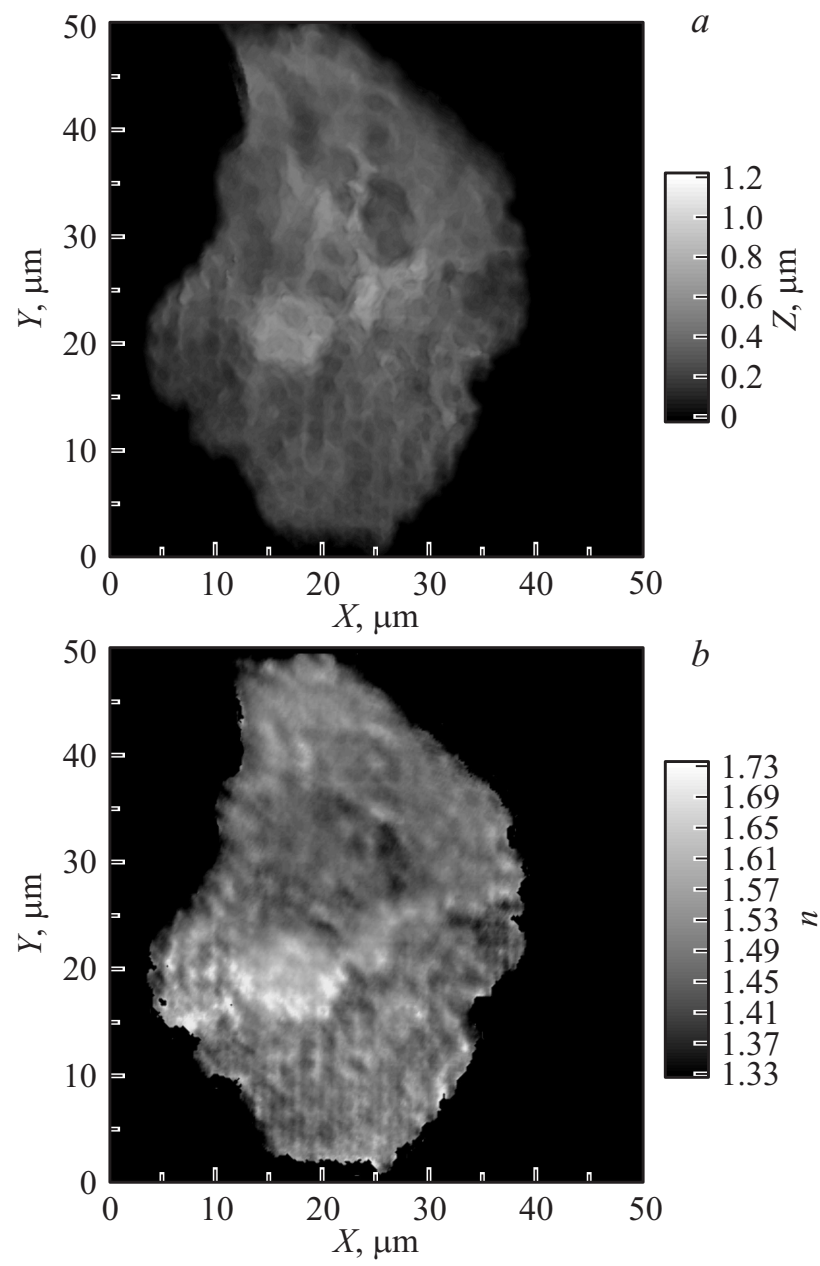

Рис. 2. Пространственные распределения толщины $(a)$ и интегрального показателя преломления $(b)$ обезвоженной клетки эпителия ротовой полости.

составляет порядка $73-83 \%$ [16]. Информацию о среднем показателе преломления обезвоженных клеток можно сопоставить со значениями среднего показателя преломления живых клеток $(n=1.358-1.375)$,

Письма в ЖТФ, 2017, том 43, вып. 20 


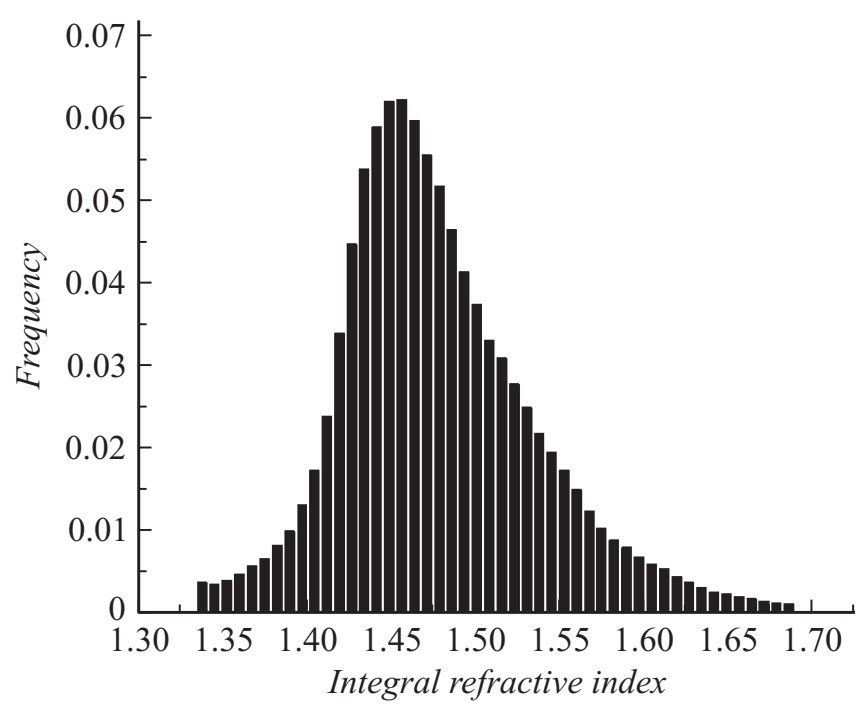

Рис. 3. Распределение интегрального показателя преломления обезвоженных клеток мазка слизистой оболочки ротовой полости человека.

полученными в работах $[8,10-12]$. Так, исходя из найденного значения среднего показателя преломления обезвоженной клетки можно оценить эту величину для живой клетки с помощью выражения

$$
n_{l c}=p_{w} n_{w}+\left(1-p_{w}\right) n_{d c},
$$

где $n_{l c}-$ показатель преломления живой клетки, $n_{d c}-$ показатель преломления обезвоженной клетки, $p_{w}$ - концентрация воды в клетке, $n_{w}$ - показатель преломления воды. Оценка показателя преломления живой клетки с помощью выражения (2) дает значения $n_{k}=1.357-1.372$, что находится в хорошем согласии с данными, представленными в работах $[8,10-12]$.

Одним из значительных преимуществ изучения обезвоженных клеток является возможность определения искомых параметров с более высокой точностью. Как нетрудно видеть из формул (1), увеличение разности фазовых набегов, внесенных клеткой в различных средах, ведет к увеличению точности определения как толщины, так и интегрального показателя преломления клетки. Однако при работе с

$4^{*}$ Письма в ЖТФ, 2017, том 43, вып. 20 
живыми клетками использование сред со значительно различающимися показателями преломления оказывается невозможным, так как живая клетка, помещенная в среду с низкой осмотической концентрацией, будет создавать избыточное гидростатическое давление на раствор, что может приводить к разрыву мембраны, гибели клетки и изменению ее морфологических характеристик. В связи с этим для определения показателя преломления живых клеток голографическим методом используются среды с одинаковой осмотической концентрацией, разность показателей преломления которых обычно не превышает 0.007 [9,11]. Принимая во внимание типичные параметры живых клеток [11], легко оценить абсолютную ошибку измерения показателя преломления как $\delta n=1.06 \delta \varphi$, где $\delta \varphi-$ абсолютная погрешность измерения фазового запаздывания.

При исследовании же обезвоженных клеток отсутствие подобных ограничений позволяет использовать среды со значительно большей разностью показателей преломления (в нашем случае разница показателей преломления воздуха и физиологического раствора составляла 0.336). Абсолютная ошибка определения показателя преломления при этом может быть оценена как $\delta n=0.19 \delta \varphi$. Учитывая сделанную выше оценку абсолютной погрешности измерения фазового запаздывания, ошибку в определении толщины клетки можно оценить как $0.02 \mu \mathrm{m}$. Помимо отсутствия жестких ограничений на свойства оптических сред, используемых в голографическом методе измерения интегрального показателя преломления, уменьшение погрешности измерений при работе с мертвыми обезвоженными клетками достигается также благодаря отсутствию временны́х флуктуаций фазы из-за возможного движения клеток.

Таким образом, в настоящей работе впервые проведены измерения пространственных распределений показателя преломления обезвоженных клеток эпителия ротовой полости голографическим методом и найден средний показатель преломления таких клеток. Проведено сравнение полученных результатов с данными о показателях преломления живых клеток. Показано, что проведение исследований на обезвоженных клетках обладает рядом преимуществ, в частности позволяет повысить точность таких измерений. Полученные результаты и разработанная методика могут быть использованы для анализа патологических процессов в клетках и тканях.

Письма в ЖТФ, 2017, том 43, вып. 20 
А.В. Белашов выражает благодарность за финансовую поддержку Фонду содействия развитию малых форм предприятий в научнотехнической сфере.

\section{Список литературы}

[1] Lee K. et al. // Sensors. 2013. V. 13. N 4. P. 4170-4191.

[2] Belashov A.V., Petrov N.V., Semenova I.V., Vasyutinskii O.S. // Proc. SPIE. 2015. N 9529. P. $95290 \mathrm{G}(1-7)$.

[3] Pham H.V. et al. // PloS One. 2013. V. 8. N. 2. P. e55676.

[4] Memmolo P. et al. // Cytometry A. 2014. V. 85. N 12. P. 1030-1036.

[5] Belashov A.V. et al. // Opt. Lett. 2016. V. 41. N 21. P. 5035-5038.

[6] Miniotis M.F., Mukwaya A., Wingren A.G. // PloS One. 2014. V. 9. N 9. P. e106546.

[7] Park Y. et al. // Proc. of the National Academy of Sciences. 2008. V. 105 . N 37. P. $13730-13735$.

[8] Curl C. L. et al. // Cytometry A. 2005. V. 65. N 1. P. 88-92.

[9] Rappaz B. et al. // Opt. Express. 2005. V. 13. N 23. P. 9361-9373.

[10] Sung Y. et al. // Phys. Rev. Appl. 2014. V. 1. N 1. P. 014002.

[11] Rappaz B. et al. // Opt. Lett. 2008. V. 33. N 7. P. 744-746.

[12] Bereiter-Hahn J., Fox C.H., Thorell B. // J. Cell. Biol. 1979. V. 82. P. 767-779.

[13] Борисенко А.В., Григоровский В.В., Тимохина Т.А. // Рос. стоматолог. журн. 2012. № 4. C. 7-12.

[14] Pan F. et al. // Opt. Express. 2011. V. 19. N 5. P. 3862-3869.

[15] Belashov A.V., Petrov N.V., Semenova I.V. // Opt. Express. 2014. V. 22. N 23. P. 28363-28376.

[16] Ling G.N. // Physiol. Chem. Phys. Med. NMR. 2004. V. 36. N 1. P. 1-20.

Письма в ЖТФ, 2017, том 43, вып. 20 